\title{
INTERthesis
}

Revista

Internacional

Interdisciplinar INTERthesis

\section{DO DESENVOLVIMENTO LOCAL AO ECODESENVOLVIMENTO TERRITORIAL ${ }^{1}$}

\author{
Paulo Freire Vieira ${ }^{2}$
}

\section{Resumo:}

$\mathrm{O}$ artigo coloca em foco as limitações do enfoque de desenvolvimento territorial face ao agravamento da crise socioecológica contemporânea. Argumenta-se que a superação dessas limitações poderia ser efetivada a partir de um diálogo com os teóricos do ecodesenvolvimento - um enfoque sistêmico de planejamento e gestão que emergiu duas décadas antes da Cúpula da Terra. Na parte conclusiva, são oferecidos subsídios exploratórios para uma reflexão centrada na busca de articulação, em rede, de coletivos transdisciplinares de pesquisadores-educadores sensíveis à experimentação criativa com o modelo híbrido de ecodesenvolvimento territorial, nos próximos tempos.

Palavras-chave: Desenvolvimento territorial. Ecodesenvolvimento. Ecodesenvolvimento territorial. Complexidade. Transdisciplinaridade

\section{Introdução}

Desde a época dos preparativos para a Conferência de Estocolmo, em 1972, a tomada de consciência dos processos de degradação intensiva do meio ambiente biofísico e construído - em escala global - tem mobilizado a atenção da opinião pública nos cinco continentes. A revolução ambiental (NICHOLSON, 1970) passou a influenciar decisivamente a reflexão sobre o fenômeno do desenvolvimento, dentro e fora da academia. De um ponto de vista inovador, começou a ser questionada a legitimidade de uma concepção que coloca a "ideologia economicista" (BOURG, 1996) no comando dos processos de modernização. Esta tomada de consciência inspirou também uma percepção mais nítida dos impactos ecológicos e sociais

\footnotetext{
${ }^{1}$ Este artigo foi apresentado oralmente no VI Congresso Internacional Sistemas Agroalimentares Localizados - os SIAL face às oportunidades e aos desafios do novo contexto global em maio de 2013, na cidade de Florianópolis, SC, Brasil.

2 Doutor em Ciência Política pela Ludwig-Maximilians-Universität München, Alemanha. Professor titular do departamento de sociologia e ciência política da Universidade Federal de Santa Catarina e pesquisador do CNPq. Coordena o Núcleo Interdisciplinar de Meio Ambiente e Desenvolvimento, vinculado ao Programa de Pós-Graduação em Sociologia Política da Universidade Federal de Santa Catarina, Florianópolis, SC, Brasil. E-mail: vieira.p@cfh.ufsc.br
} 
gerados pela "tecnociência sem consciência" (MORIN, 1996). Por outro lado, apesar do peso assumido pelas controvérsias de natureza conceitual-teórica e ético-política, intensificou-se a pesquisa sobre os condicionantes estruturais da crise socioecológica, no âmbito de uma ecologia humana baseada no novo paradigma sistêmico-complexo (BERTALANFFY, 1968, ATLAN, 1979, BATESON, 1996, MORIN; KERN, 1993, PASSET, 1979, BERKES; COLDING; FOLKE, 2003, VIEIRA; BERKES; SEIXAS, 2005).

A utilização predatória dos recursos naturais de uso comum, os "commons", as curvas exponenciais de crescimento demográfico, a hiperurbanização, a exclusão social da maior parte da população mundial, a persistência das assimetrias nas relações Norte-Sul e o agravamento tendencial das chamadas "mudanças ambientais globais" passaram a colocar problemas qualitativamente novos às sociedades modernas e, especialmente, à comunidade de cientistas associados a este novo campo de investigação inter e transdisciplinar. As diferentes percepções do mundo natural, as práticas decorrentes, seus impactos destrutivos e as reinterpretações sucessivas das transformações operadas na dinâmica dos ecossistemas e das paisagens conferem uma extraordinária densidade às investigações que vêm sendo efetuadas à luz desta perspectiva ecológico-humana (DANSEREAU, 1999).

No transcurso de sua evolução, a biosfera se diferenciou em função das condições climáticas, do substrato geológico, da informação genética disponível e da ação dos organismos vivos. Transformou-se assim num macrossistema complexo, composto de ecossistemas. Apesar de integrarem um continuum mais amplo, os ecossistemas são dotados de características mais ou menos específicas, o que os torna passíveis de serem assumidos como unidades básicas para a pesquisa das complexas inter-relações sociedade-natureza.

A representação dominante de um ecossistema é a de um sistema capaz de absorver a energia solar, de convertê-la em energia química por meio da fotossíntese e de distribuir esta energia química de forma a assegurar a manutenção de sua estrutura funcional. Os mecanismos de controle intimamente associados à diversidade biológica permitem aos ecossistemas manter sua persistência no tempo enquanto estruturas funcionais e dinâmicas. Mas, ao longo do processo de hominização, a espécie humana tem se aproveitado dessa plasticidade para conceber estratégias de apropriação e uso dos recursos naturais que vêm colocando 
seriamente em risco os mecanismos de auto-regulação da ecosfera (MEADOWS; MEADOWS; RANDERS, 2004, LOVELOCK, 1991, MORIN; KERN, 1993, VIEIRA; RIBEIRO, 1999).

Um sistema aberto, visto como um conjunto de elementos inter-relacionados, que tende ao alcance de determinados estados, surge, nessa perspectiva, como uma totalidade estruturada em níveis diferenciados de organização. Por convenção, e numa acepção não normativa, os níveis de onde convergem as funções são qualificados de inferiores relativamente àqueles para os quais as funções convergem. A passagem a um nível de organização superior traduz-se pelo surgimento de uma nova lógica de comportamento, de novos mecanismos e formas de auto-regulação não identificáveis nos níveis inferiores. Por outro lado, cada nível decorre da articulação daqueles que lhe são inferiores e participa da formação daqueles que lhe são superiores. Cada qual contribui, por meio da ação de processos de retroalimentação ou feedback, para a harmonização das funções que o produzem. Há, portanto, o reconhecimento de que a existência do todo e das partes condicionam-se mutuamente: "as partes estão no todo, que está nas partes" (BERTALANFFY, 1968, KOESTLER, 1981, LABORIT, 1974, 1986, MORIN, 1998, BAREL, 1989, LASZLO, 1981, BATESON, 1977).

Essas considerações cursivas nos ajudam a perceber que o tratamento das incertezas e ambivalências, que caracterizam a busca de compreensão da dinâmica não linear dos sistemas socioecológicos, exige o aprendizado de um "pensamento complexo", em princípio capaz de

situar todo acontecimento, informação ou conhecimento em relação de inseparabilidade com seu meio ambiente - cultural, social, econômico, político e, é claro, natural. Aprendemos não só a situar um acontecimento em seu contexto. Além disso, aprendemos a perceber melhor como este contexto o modifica, ajudando-nos a entendê-lo de outra maneira. Um tal pensamento torna-se, inevitavelmente, um pensamento sintonizado com a problemática da complexidade, pois não basta inscrever todas as coisas ou acontecimentos num 'quadro' ou numa 'perspectiva'. Trata-se de procurar sempre as relações e inter-retro-ações entre cada fenômeno e seu contexto, as relações de reciprocidade todo/partes: como uma modificação local repercute sobre o todo e como uma modificação do todo repercute sobre as partes. Ao mesmo tempo, a intenção é reconhecer a unidade na diversidade, a diversidade na unidade; é reconhecer, por exemplo, a unidade humana em meio às diversidades individuais e culturais, as diversidades individuais e culturais em meio à unidade humana. Enfim, um pensamento unificador abre-se de si mesmo para o contexto dos contextos: o contexto planetário. Para seguir por este caminho, o problema não é tanto o de se abrir as fronteiras entre as disciplinas, mas o de se transformar 
aquilo que gera essas fronteiras: os princípios organizadores do conhecimento (MORIN, 2000, p. 25).

Dessa forma, caos e ordem, unidade e diversidade, continuidade e descontinuidade, reversibilidade e irreversibilidade se interpenetram numa imagem unitária de seres-humanos-em-ecossistemas (GUNDERSON; HOLLING, 2002).

Considerada à luz dessas premissas, a crise socioecológica global constitui ao mesmo tempo uma crise das nossas representações convencionais - dualistas da natureza e uma crise das nossas relações com ela. Ela exprime o surgimento de um novo limiar de complexificação do processo histórico de inter-relacionamento dinâmico, envolvendo os sistemas socioculturais e seu substrato biofísico e construído. Vem se tornando assim mais nítida a impressão de que "os grandes problemas que desafiam a humanidade são tão complexos e tão interdependentes que as instituições e planos de ação tradicionais já não são capazes de superá-los, e nem mesmo de enfrentá-los em seu conjunto" (MEADOWS et al. 1972, p. 10) (DEUTSCH, 1977, DUPUY, 1980, 1983, 2002). Ao longo dos últimos tempos, as noções de incerteza, irreversibilidade, resiliência ecossistêmica, capacidade adaptativa, aprendizagem adaptativa, auto-organização, transdisciplinaridade e "ecologia da ação", entre outras, passaram a oferecer novos pontos de referência para uma compreensão cada vez mais acurada desse fenômeno, inspirando a pesquisa de novas estratégias de intervenção corretiva (HOLLING; BERKES; FOLKE, 1998, GUNDERSON; HOLLING, 2002, VIEIRA; WEBER, 2000, AUBIN, 1991, 1994, BOTKIN, 1990, BERKES; FOLKE, 1998, DANSEREAU, 1999, ANDREEWSKI, 1991, CHAUMONT; PARIJS, 1991).

\section{Repensando o desenvolvimento local}

Esta abertura a uma representação sistêmico-complexa da crise, bem como dos espaços de manobra que dispomos na busca de alternativas, condicionou a elaboração do enfoque de ecodesenvolvimento, no início dos anos 1970. Devemos à equipe interdisciplinar sediada no Centre International de Recherche sur l'Environnement et le Développement, em Paris, uma contribuição ímpar ao aprofundamento gradual dessas ideias no contexto do follow up da Conferência de Estocolmo (CIRED, 1986, SACHS, 1980). A partir da denúncia do viés economicista/produtivista ainda hoje profundamente enraizado nos nossos sistemas 
de planejamento e gestão, o meio ambiente passou a ser considerado como uma dimensão constitutiva das políticas de desenvolvimento. Os avanços da nova ecologia humana sinalizavam a urgência de uma transformação paradigmática de crenças, valores e atitudes relativamente aos padrões de interação dos seres humanos com o meio ambiente biofísico e construído, distinguindo assim essa posição de outras linhas de reflexão teórica, nos campos do desenvolvimento e do planejamento (DAG, 1975, GLAESER, 1984, VIEIRA; RIBEIRO, 1999, COLBY, 1990).

As novas démarches de planejamento sugeridas pela equipe do CIRED contemplavam, simultaneamente, (i) a dimensão relativa à base de recursos naturais necessária à subsistência de grupos humanos e, de maneira simétrica, à função de assimilação dos dejetos gerados pelas atividades de produção e consumo; (ii) a dimensão espacial, entendida como o lócus dos processos coevolutivos de adaptação inventiva às oportunidades e limitações impostas pelo meio; e, finalmente, (iii) a dimensão da qualidade dos hábitats, correspondendo à infraestrutura física e institucional que influencia a qualidade de vida das populações (habitação, trabalho, recreação, auto-realização existencial) e a própria viabilidade ecológica dos sistemas socioculturais no longo prazo (GODARD; SACHS, 1975).

Além disso, o esforço investido numa reaproximação dos espaços da economia e da ética pela via da nova "perspectiva ecológica" (DANSEREAU, 1999) passou a levar em conta a percepção das limitações congênitas dos indicadores usuais de eficiência econômica e de criação de riqueza social. A ideia de uma nova economia de sistemas socioecológicos complexos - a ecossocioeconomia comparecia, já na época das reuniões preparatórias, para a Conferência de Estocolmo, conservando desde então toda a sua atualidade. ${ }^{3}$ Nesse caso, o desafio crucial colocado aos pesquisadores consistia em se

abrir a economia a novas abordagens (no caso, aquela dos sistemas autoorganizadores), a novas dimensões (energética, informacional) e a novos instrumentos de avaliação (não monetários), suscetíveis de apreender aqueles certos aspectos do real que escapam aos instrumentos tradicionais de análise (PASSET, 1992, p. 28).

\footnotetext{
${ }^{3}$ Este termo foi cunhado por Karl William Kapp (1987), economista de origem alemã e um dos mais brilhantes precursores do debate ecológico-político europeu dos anos 1970.
} 
Além disso, a ruptura com o mainstream da socioeconomia do desenvolvimento do pós-guerra - marcado pela dominância das teorias de corte neoclássico, keynesiano e marxista - colocou em evidência a necessidade de uma postura etnográfica nas análises do funcionamento das "economias reais", ou seja, de um novo estilo de investigação interdisciplinar e sensível à importância da dimensão sociocultural sempre presente nas relações econômicas (SACHS, 2007). Desgastava-se assim a confiança ingênua depositada nas supostas virtudes de um economicismo abusivo, que ainda hoje não hesita em degradar o patrimônio natural e cultural da humanidade em nome de interesses estritamente privados e imediatistas.

A intenção era, sobretudo, a de ajustar o desenho das novas estratégias de ação à extraordinária variedade de culturas humanas, procurando

reagir à moda predominante das soluções pretensamente universalistas e das fórmulas generalizantes. Em vez de atribuir uma importância excessiva à ajuda externa, depositava-se um voto de confiança na capacidade das populações de identificarem seus próprios problemas e de buscarem para os mesmos soluções originais [...]. A palavra-chave aqui é 'criatividade': a engenhosidade em transformar os elementos do ambiente (natural $\mathrm{e}$ cultural) em recursos úteis (SACHS, 1986, p. 18).

O enfoque analítico do CIRED colocava também em primeiro plano a fixação de critérios alternativos para a seleção de novas opções tecnológicas e para o exercício do controle democrático dessas inovações (REDDY, 1977). As referências ao conceito de tecnologias apropriadas (no sentido de compatíveis com a singularidade de cada contexto histórico e socioecológico) passaram a constituir um eixo norteador do esforço de pesquisa promovido no CIRED. Buscava-se superar o viés reducionista - típico daquela época - que restringe a regulação socioeconômica das inovações técnicas ao espaço bidimensional do capital e do trabalho. A intenção era repensar a técnica vista como um fenômeno multidimensional por excelência, cuja gestão deveria estar comensurada a um novo projeto de sociedade ecologicamente prudente e "convivial" (SACHS et al., 1981, ILLICH, 2011, FONTAN; VIEIRA, 2011).

Um corolário importante desse debate centrado na construção de um novo estilo tecnológico diz respeito ao fomento de sistemas produtivos locais integrados para um desenvolvimento local autocentrado, num cenário geopolítico marcado pela persistência das tradicionais assimetrias Norte-Sul. Tomando por modelo os ciclos 
ecológicos e procurando tirar o melhor partido possível das relações de complementaridade entre as mais diversas atividades envolvidas, a intenção era promover uma bio-industrialização descentralizada no meio rural. Avanços substanciais apontando nessa direção deveriam pressupor a delimitação das margens de manobra para a definição de estratégias "não miméticas" de desenvolvimento face à experiência dos países supostamente "desenvolvidos". Pois, como seria possível descortinar espaços alternativos de regeneração cultural em sintonia com os princípios (interdependentes!) de endogeneidade, equidade e prudência ecológica, sem romper pela base com a síndrome de violência estrutural (GALTUNG, 1996; BAECKER, 1996) subjacente ao projeto de expansão planetária da civilização industrial-tecnológica? (DUPUY, 1980, SACHS, 2007, PASSET, 1979, DAG, 1975, 2002, MCHARG, 1969).

Segundo Godard (1998, p. 220-221),

\begin{abstract}
em termos analíticos o ecodesenvolvimento repousa no estudo das interdependências e das margens de liberdade entre as principais variáveis daquilo que denominamos 'estilos de desenvolvimento'. É neste tabuleiro do desenvolvimento que se joga o jogo da harmonização a ser levado em conta pelos planejadores. Três blocos de variáveis de ação podem ser aqui distinguidos: o polo da demanda social, em torno do conceito de estilo de vida; o polo da oferta (a gestão dos recursos naturais e o aprovisionamento em termos de matérias primas e de energia, a localização das atividades econômicas e a organização espacial, as técnicas - produtos e procedimentos - e o meio ambiente propriamente dito. $\mathrm{O}$ jogo da harmonização consiste em inventar uma estratégia para transformar ao mesmo tempo os estilos de vida e de consumo, os estilos tecnológicos, os estilos de gestão do espaço territorial, os modos de gestão dos recursos naturais e o aprovisionamento energético, num sentido mais compatível com a busca de satisfação de necessidades básicas das populações e de preservação do meio ambiente.
\end{abstract}

Finalmente, além da valorização do know-how daquelas comunidades locais que souberam manter, ao longo do tempo, uma relação ecologicamente prudente de utilização dos ecossistemas e das paisagens - as chamadas culturas da conservação (GADGIL, 1998, 1999; BERKES, 1998) - a aplicação consistente deste enfoque exigia a consolidação de sistemas de gestão ao mesmo tempo integrada e compartilhada de recursos naturais entendidos como recursos comuns (BROMLEY, 1992, VIEIRA; BERKES; SEIXAS, 2005, OST, 1995, ARMITAGE; BERKES; DOUBLEDAY, 2007, OLSSON; FOLKE; BERKES, 2004, OLLAGNON, 2000).

Por ocasião da Cúpula da Terra, no Rio de Janeiro, vinte anos após Estocolmo, a difusão do conceito de sustentabilidade contribuiu para polarizar o 
debate em torno de duas opções possíveis de superação da crise socioecológica (LÉVESQUE, 2009). Do ponto de vista dos adeptos do critério de sustentabilidade forte, os princípios reguladores das novas estratégias de desenvolvimento decorreriam, basicamente, dos termos de referência do enfoque "clássico" de ecodesenvolvimento. Repetimos aqui, a dinâmica de planejamento estratégico é caracterizada como um "jogo de harmonização" inventivo, baseado no pensamento sistêmico-complexo e norteado por um conjunto interdependente de postulados éticos: satisfação de necessidades básicas, equidade, self-reliance, subsidiaridade, economia plural e prudência ecológica. Neste caso, a economia é reduzida à sua função de simples instrumento "destinado a viabilizar a promoção da justiça social e da sustentabilidade socioecológica cujo conteúdo resulta de uma deliberação política" (LAVILLE, 2005, p. 336). E mais: "na versão da sustentabilidade forte, a dimensão socioecológica só se torna traduzível em avanços constatáveis por meio da confrontação das esferas não mercantis e não monetárias articuladas a mercados regulados" (LAVILLE, 2005, p. 337).

Por sua vez, na versão de sustentabilidade fraca, as dinâmicas de desenvolvimento continuam tributárias de um aumento contínuo dos níveis atuais de produção e consumo, não obstante, o apelo a corretivos tecnológicos e gerenciais ex post de sintomas isolados da poli-crise global - a exemplo da internalização de externalidades por meio do cálculo econômico-monetário, configurando o paradoxo da busca de um suposto "ritmo otimizado de... destruição da natureza!" (MARÉCHAL, 2005, p. 44). No mesmo diapasão, Passet (2000, p. 421) acredita que "a economia neoliberal só consegue se apropriar do enfoque de desenvolvimento sustentável mutilando-o e desnaturando-o", ou seja, submetendo as esferas do social e do ecológico à hegemonia da regulação pelo mercado competitivo.

Do ponto de vista adotado neste artigo, esta ambição de dotar as sociedades contemporâneas de melhores instrumentos para uma gestão da crise socioecológica, supostamente eficiente em termos econômicos, mas insensível à dimensão sistêmica do "mau desenvolvimento", constitui uma espécie de terapia superficial e míope para uma disfunção estrutural de extrema gravidade, a saber: a prevalência da ética antropocêntrica-utilitarista de domínio sobre a natureza no desenho de novos projetos de sociedade e de novos parâmetros civilizadores.

\section{Desenvolvimento territorial: potencialidades e limitações}

R. Inter. Interdisc. INTERthesis, Florianópolis, v.10, n.2, p. 119-141, Jul./Dez. 2013 
Contrapondo-se às orientações de ajuste neoliberal das economias nacionais típicas do cenário do final dos anos 1980, o enfoque territorial tem sido utilizado, desde então, para redesignar o local vinculando-o (i) aos chamados efeitos de proximidade (ZAOUAL, 2005); (ii) aos critérios de endogeneidade e especificidade; (iii) à lógica da reciprocidade na valorização de recursos territoriais; e, finalmente (iv), aos regimes territoriais de governança. A intenção de requalificar o critériochave de endogeneidade, tornando-o um eixo estruturante das novas estratégias de desenvolvimento local, indica "que existem modos de organização da vida social e da produção que são ancorados territorialmente, ou seja, para os quais o contexto sociocultural e histórico (a especificidade dos territórios) é importante" (GUMUCHIAN; PECQUEUR, 2007, p. 5). Assim, a diretriz de territorialização do desenvolvimento local passou a evidenciar "a eficácia das relações não exclusivamente mercantis entre os homens para valorizar as riquezas de que eles dispõem" (PECQUEUR, 1989, p. 17).

Consideradas dessa forma, as novas dinâmicas territoriais de desenvolvimento estariam inseridas numa estratégia de adaptação "ofensiva" à globalização: abertura de novos espaços de manobra para uma recomposição social ajustada a um novo projeto de sociedade. Para as empresas, trata-se de escapar da concorrência induzida pelos preços e pelos custos de produção, privilegiando a dimensão da qualidade territorial e as relações de cooperação sinérgica entre os diversos atores sociais envolvidos (PECQUEUR, 2006). A inovação desempenha aqui um papel fundamental. Além disso, valorizando a adoção de um novo padrão de funcionamento centrado no nível local-comunitário, o enfoque territorial se distancia dos processos hierárquicos e piramidais que se tornam cada vez menos adaptados às condições atuais da abertura global das economias e das culturas.

Apontando neste sentido, Raud (1998, p. 255) reconhece que

a vitalidade econômica das experiências classificadas como sendo expressões de desenvolvimento territorial parece depender de três fatores principais: (i) o fato de terem conservado um espírito de abertura face às inovações internas ou externas; (ii) da existência de indivíduos bem dotados em termos de novas competências; e (iii) da consolidação de instituições dotadas de flexibilidade suficiente para a indução de mudanças ajustadas às necessidades do momento. Além disso, essas dinâmicas coletivas podem ser explicadas também por meio do recurso à noção de 'proximidade'. Numa primeira aproximação, o termo refere-se a um processo especial de aprendizagem coletiva, baseada no sentimento 
comunitário dos atores, para além da expressão de suas diferenças e conflitos.

Por sua vez, Courlet (2008, p. 119) tem insistido no reconhecimento de que o enfoque territorial leva em conta a especificidade de uma "meso-economia do território", em cujo modelo de análise comparecem os conceitos de sistema produtivo localizado, meios inovadores, cluster, sistema produtivo urbano, recurso territorial e governança territorial.

Todavia, já se tornou um lugar-comum reconhecer que

as pesquisas sobre territórios, se bem que numerosas, só muito raramente abordam a questão do ponto de vista da complexidade, mesmo se levarmos em conta que "o território possui todas as características de um sistema complexo, no seio do qual ele adquire uma real coerência (COURLET, 2008, p. 34).

Magnaghi (2005, p. 83) compartilha esse mesmo ponto de vista, ao admitir a necessidade de se promover "a ativação de relações positivas entre três componentes essenciais, cujas interações recíprocas respondem pela produção de territórios: o ambiente biofísico, o ambiente construído e o ambiente social e humano".

As referências cada vez mais numerosas ao conceito de sistemas agroalimentares localizados (SIAL), na literatura sobre "territórios sustentáveis", merece aqui uma consideração à parte. Desde o início dos anos 1990, esse conceito designa um tipo especial de sistema produtivo local composto de "organizações de produção e de serviços (unidades de produção agrícola, empresas agroalimentares, comerciais, de serviços) associadas por suas características e seu funcionamento em um território específico" (CIRAD, 1996). A preocupação pela qualificação dos produtos - um elemento central do modelo analítico correspondente, exige, não só a construção de novos dispositivos institucionais e de novas modalidades de regulação de estratégias individuais, coletivas e públicas, mas, também, pressupõe a pesquisa de novas interfaces entre os conhecimentos de atores locais, pesquisadores e técnicos, além de revelar a complexidade envolvida na imbricação dos processos de produção e consumo de alimentos.

Todavia, no discurso dos promotores da cultura industrialista-consumista globalizada - a exemplo do que vem ocorrendo com a apropriação social da noção de 
desenvolvimento sustentável - a territorialidade frequentemente passa a ser valorizada como simples objeto de interesse mercantil e especulativo. Esta maneira de abordar e de intervir no espaço territorial nos leva a apropriar e a consumir, de forma predatória - e, portanto, insustentável no longo prazo - aquilo que a territorialidade pode significar e gerar em termos de vantagens econômicas no curto prazo. O resultado torna-se um tipo de exploração econômica corrosiva da territorialidade autêntica, destrutiva do capital social e também do meio ambiente e dos recursos naturais (ALBAGLI, 2004, p. 63-64).

Em síntese, a argumentação desenvolvida até aqui fundamenta a hipótese de que os componentes essenciais do debate atual sobre dinâmicas territoriais de desenvo/vimento já compareciam no arcabouço conceitual do enfoque "clássico" de ecodesenvolvimento dos anos 1970 (VIEIRA, 2006, RAUD, 1998). Todavia, na análise das novas dinâmicas territoriais emergentes a consideração da problemática socioecológica global permanece deficitária. Uma compreensão lúcida dos desafios que têm emergido no atual cenário de crise do capitalismo globalizado - ou "pósfordista" - dependeria assim da consideração de duas lógicas específicas - ou de duas "problemáticas cruzadas" (RAUD, 1998). Por um lado, seria indispensável resguardar uma entrada sistêmica e globalizante na reflexão sobre alternativas de gestão integrada e compartilhada (i) de recursos naturais (renováveis e não renováveis); (ii) do espaço territorial; e (iii) da qualidade dos hábitats. E por outro, parece-me evidente a urgência de uma reflexão aprofundada sobre a complexidade envolvida nos processos de criação/"perenização" de recursos territoriais, mobilizando, para tanto, uma abordagem renovada dos processos de desenvolvimento territorial. A noção de recurso territorial é investida, assim, do estatuto de eixo norteador de um processo de hibridização dos dois enfoques territorial e ecodesenvolvimentista (PECQUEUR; VIEIRA, 2013, PECQUEUR, 2004).

Essa construção híbrida aponta assim no sentido da desconstrução pela base do paradigma de organização "fordista" das sociedades contemporâneas. Ela combina uma abordagem sensível à singularidade da dimensão do "território" com uma abordagem ecológica de escopo globalizante. Trata-se, portanto, de combinar as problemáticas (i) da autonomia relativa das dinâmicas locais; (ii) da articulação dos diversos níveis de integração regional; e (iii) da transformação do padrão dominante de inter-relacionamento entre os agentes econômicos, o Estado e a sociedade civil organizada. Pois, como já foi mencionado acima, a maior parte dos macro problemas (multidimensionais, interdependentes e transescalares) a serem enfrentados, atualmente, num cenário de intensificação da crise global, não se 
enquadram mais na tradicional estrutura "top-down" das tomadas de decisão no campo do planejamento e da gestão das novas estratégias de desenvolvimento. A ênfase colocada na instituição de novos sistemas de governança territorial pode ser melhor compreendida à luz dessas premissas, levando-se em conta que a construção de uma nova geração de políticas públicas integradas e compartilhadas deverá exigir uma mobilização de estruturas multiatores para além das hierarquias político-administrativas convencionais (CARLSSON; SANDSTRÖM, 2008, GUNDERSON; HOLLING, 2002). O estágio ainda embrionário dessa reflexão na comunidade científica internacional reflete a magnitude dos desafios teóricos e práticos envolvidos na gestão desses processos de recriação institucional e de aprendizagem social transformadora.

\section{Implicações para uma nova agenda de pesquisa-ação-formação para o ecodesenvolvimento territorial}

Como dotar essas inovações conceituais, teóricas e metodológicas do nível de coerência e legitimidade social considerado à altura dos desafios que cercam, na prática cotidiana, a concretização dessas mutações cognitivas e comportamentais de que tanto necessitamos?

Ao que tudo indica, no mínimo, teríamos que avançar no sentido do fortalecimento institucional de comunidades científicas cada vez melhor integradas e, por implicação, cada vez mais capazes de impulsionar a realização de experimentações comparativas de pesquisa-ação-formação comunitária em "regiões-laboratório de ecodesenvolvimento territorial" (VIEIRA et al., 2011, LÉVÊQUE et al., 2000). Em outras palavras, trata-se de promover articulações em rede de coletivos inter e transdisciplinares engajados num movimento de ecopedagogia planetária e decididos a transcender as limitações do establishment acadêmico no enfrentamento das causas estruturais da crise global (ELDEN; CHISHOLM, 1993, HATCHUEL, 2000, MERMET; POUX, 2002, WEBER, 2000, SEBILLOTTE, 2001).

Num artigo clarividente publicado sob os auspícios do Programa "Ambiente, Vida e Sociedades", promovido pelo Conseil National de la Recherche Scientifique (CNRS), na França, as regiões-laboratório são caracterizadas como sendo 
zonas geográficas, muitas vezes numa escala regional, dispondo de uma certa unidade funcional, e que são definidas em função de questionamentos científicos indicando pesquisas a serem realizadas a longo prazo sobre a dinâmica dos sistemas socioecológicos. Tais questionamentos seriam provenientes seja de uma dinâmica científica, seja de uma expectativa ou demanda social reformuladas em termos científicos (LÉVÊQUE et al., 2000).

No interior das regiões-laboratório, podem ser delimitadas zonas mais ou menos instrumentalizadas para a aquisição de dados a serem coletados, seja por meio de observações diretas, seja por meio de experimentações comparativas. Essas zonas seriam de escopo mais reduzido - a exemplo de uma bacia hidrográfica, de uma parcela florestada ou de um bairro de uma aglomeração urbana. O conjunto desse dispositivo deveria ser articulado em rede, mobilizando os vários níveis de regulação das dinâmicas territoriais de desenvolvimento sustentável - do local ao global.

Para além do seu potencial de integração de grupos inter e transdisciplinares, esse instrumento poderia favorecer e nutrir (i) uma consideração mais efetiva do horizonte de longo prazo no planejamento do ecodesenvolvimento territorial, por meio de modelos prospectivos capazes de facilitar as tomadas de decisão no âmbito dos novos sistemas de governança territorial; (ii) a realização de pesquisas integradas e com perfil comparativo; (iii) a promoção do "diálogo-de-saberes" com as comunidades locais; (iv) a formação permanente de pesquisadores e de vários outros atores sociais no campo da pesquisa sobre o nexo ambiente \& desenvolvimento; e, finalmente, (v) uma inserção coordenada e duradoura de equipes e de responsáveis pela gestão das regiões-laboratório em redes transescalares.

Em resumo, trata-se não só de favorecer a experimentação criativa com uma nova modalidade de compartilhamento de saberes e experiências envolvendo pesquisadores, gestores e cidadãos. Essa abordagem poderia ajudar também a "catalizar" a realização de programas de longo fôlego de pesquisa-ação-formação transdisciplinar. Mas, para que ela saia efetivamente do papel, teremos que investir mais decididamente na constituição progressiva de um tecido social cooperativo, inspirado simultaneamente no cultivo da inteligência da complexidade (MORIN; LE MOIGNE, 2000) e numa ética ecológica que se nutre tanto da incerteza, quanto da esperança numa metamorfose regeneradora dos fundamentos da civilização 
contemporânea (DANSEREAU, 1999, MORIN; KERN, 1993, BATESON, 1996, BOHM, 1988, BOHM; EDWARDS, 1991, GALTUNG, 1996). 


\title{
FROM THE LOCAL DEVELOPMENT TO THE TERRITORIAL ECODEVELOPMENT
}

\begin{abstract}
:
This paper explores the shortcomings (from the conceptual, theoretical and ethical points of view) of the territorial development approach in taking into account the complexity inherent in the global socioecological crisis. The author seeks to highlight the need to transcend these shortcomings by way of establishing a dialogue with the ecodevelopment approach - a systemic planning concept that has emerged twenty years before the UN Summit on Environment and Development, held in Rio de Janeiro in 1992. In the last part, the author offers some exploratory guidelines to engage transdisciplinary research units in coordinated experiments with this hybrid concept of territorial ecodevelopment in the next years.
\end{abstract}

Keywords: Territorial development. Ecodevelopment. Territorial ecodevelopment. Complexity. Transdisciplinarity.

\section{DEL DESARROLLO LOCAL HACIA EL ECODESARROLLO TERRITORIAL}

\section{Resumen:}

Este artículo explora las limitaciones (en términos conceptuales, teóricos y éticos) del enfoque de desarrollo territorial frente al reto de incorporar al mismo la dimensión de la complejidad sistémica involucrada en la problemática socioecológica global. En este sentido, el autor aborda el debate sobre ecodesarrollo deflagrado en la fase de follow-up de la Conferencia de Estocolmo y considera las ventajas de una posible hibridización de los dos enfoques. En la última parte de este artículo son propuestas guías exploratorias para el diseño de una política de integración de equipos transdisciplinares sensibles a una experimentación coordenada con este concepto de ecodesarrollo territorial.

Palabras-clave: Desarrollo territorial. Ecodesarrollo. Ecodesarrollo territorial. Complejidad. Transdisciplinaridad. 


\section{Referências}

ALBAGLI, S. Território e territorialidade. In: LAGES, V. N. et al. Territórios em movimento: cultura e identidade como estratégias de inserção competitiva. Rio de Janeiro: Relume Dumará; Brasília: SEBRAE, 2004. pp. 23-70.

ANDREEWSKY, E. Systémique et cognition. Paris: Dunod, 1991.

ARMITAGE, D.; BERKES, F.; DOUBLEDAY, N. Adaptive co-management: collaboration, learning, and multi-level governance. Vancouver: University of British Columbia Press, 2007.

ATLAN, H. Entre le cristal et la fumée. Essai sur l'organisation du vivant. Paris: Éditions du Seuil, 1979.

AUBIN, J. P. Viability theory. Basel: Birkhäuser Verlag, 1991.

AUBIN, J. P. La mort du devin, l'émergence du démiurge. Paris: Seuil, 1994.

BAECKER, D. Gewalt im System. Soziale Welt 1: 92-109, 1996.

BAREL, Y. Le paradoxe et le système. Grenoble: Presses Universitaires de Grenoble, 1989.

BATESON, G. Vers une écologie de l'esprit. Paris: Le Seuil, 1977.

BATESON, G. Une unité sacrée. Quelques pas de plus vers une écologie de l'esprit. Paris: Le Seuil, 1996.

BERKES, F. Sacred ecology. Traditional ecological knowledge and resource management. Philadelphia: Taylor \& Francis, 1998.

BERKES, F.; FOLKE, C. Linking social and ecological systems. Management practices and social mechanisms for building resilience. Cambridge: Cambridge University Press, 1998. 
BERKES, F.; COLDING, J.; FOLKE, C. Navigating social-ecological systems: building resilience for complexity and change. Cambridge: Cambridge University Press, 2003.

BERTALANFFY, L. v. General systems theory. New York: Braziller, 1968.

BOHM, D. La danse de l'esprit. La Varenne: Les Editions Séveyrat, 1988.

BOHM, D. ; EDWARDS, M. Pour une révolution de la conscience. Paris: Éditions du Rocher, 1991.

BOTKIN, D. B. Discordant harmonies. A new ecology for the 21th century. New York: Oxford University Press, 1990.

BOURG, D. Les scénarios de l'écologie. Paris: Hachette, 1996.

BROMLEY, D. W. Making the commons work. Theory, practice and policy. San Francisco: ICSP, 1992.

CARLSSON, L.; SANDSTRÖM, A. Network governance of the commons. Int.J. of the Commons, n. 2, p. 33-54. 2008.

CHAUMONT, J. M.; PARIJS, V. Les limites de l'inéluctable. Penser la liberté au seuil du troisième millénaire. Bruxelles: De Boeck, 1991.

CIRAD. Systèmes agroalimentaires localisés: organisations, innovations et développement local. Montpellier: Cirad, 1996.

CIRED. Rapport scientifique 1973-1986. Paris: EHESS, 1986.

COLBY, M. Ecology, Economics and social systems. The evolution of the relantionship between environmental management and development. Pennsylvania: University of Pennsylvanis Press, 1990.

COURLET, C. L'économie territoriale. Grenoble: Presses Universitaires de Grenoble, 2008. 
DAG, H. What now: another development. Uppsala: DHF, 1975.

DANSEREAU, P. Uma preparação ética para a mudança global: prospecção ecológica e prescrição moral. In: VIEIRA, P. F.; RIBEIRO, M. A. Ecologia humana, ética e educação. A mensagem de Pierre Dansereau. Florianópolis: APED, 1999. p. 299-370.

DEUTSCH, K. W. Eco-social systems and eco-politics. Paris: UNESCO, 1977.

DUPUY, J. P. Introdução à crítica da ecologia política. Rio de Janeiro: Civilização Brasileira, 1980.

DUPUY, J. P. L'auto-organisation: de la physique au politique. Paris: Seuil, 1983.

DUPUY, J. P. Pour un catastrophisme éclairé. Quand l'impossible est certain. Paris: Éditions du Seuil, 2002.

ELDEN, M.; CHISHOLM, R. F. Emerging varieties of action research. Human Relations, v. 46, n. 2, p. 121-142. 1993.

FONTAN, J. M.; VIEIRA, P. F. Por um enfoque sistêmico, ecológico e "territorirializado". In: TREMBLAT, G.; VIEIRA, P. F. O papel da universidade no desenvolvimento local. Experiências brasileiras e canadenses. Florianópolis: APD / SECCO, 2011. p. 19-80.

GADGIL, M. Conservation: Where are the people? The Hindu Survey of the Environment, v. 98, p. 107-137. 1998.

GADGIL, M. New meanings for old knowledge: the People's Biodiversity Registers Programme. Bangalore: CES, 1999.

GALTUNG, J. Cultural peace: some characteristics. In: UNESCO. From a culture of violence to a culture of peace. Paris: UNESCO, 1996.

GLAESER, B. Ecodevelopment. Concepts, projects, strategies. Oxford: Pergamon Press, 1984. 
GODARD, O. L'écodéveloppement revisité. Economies et Sociétés, v. 36, n. 1, p. 213-229. 1998.

GODARD, O.; SACHS, I. L'environnement et la planification. In : BARREAU, M. et al. Environnement et qualité de la vie. Paris: Guy le Prat, 1975. p. 207-247.

GUMUCHIAN, H.; PECQUEUR, B. La ressource territoriale. Paris: Economica/Anthropos, 2007.

GUNDERSON, L. H.; HOLLING, C. S. Panarchy. Understanding transformations in human and natural systems. Washington: Island Press, 2002.

HATCHUEL, A. Recherche, intervention et production de connaissances. In: COURLET, $C$. et al. Recherches pour et sur le développement territorial. Symposium INRA-DADP de Montpellier, 11, 12 janv. Paris: Editions INRA, 2002. p. 27-40.

HOLLING, C. S; BERKES, F.; FOLKE, C. Science, sustainability and resource management. In: BERKES, F.; FOLKE, C.; COLDING, J. Linking social and ecological systems: management practices and social mechanisms for building resilience. Cambridge: Cambridge University Press, 1998.

ILLICH, I. Oeuvres complètes. Paris: Fayard, 2011.

KOESTLER, A. The three domains of creativity. In: DUTTON, D.; KRAUSZ, M. The concept of creativity in science and art. Boston: Martinus, 1981. p. 1-18.

LABORIT, H. La nouvelle grille pour décoder le message humain. Paris: Laffont, 1974.

LABORIT, H. La complexité de l'interdépendence dans les systèmes vivants. In: Science et pratique de la complexité. Paris: La Documentation Française, 1986.

LASZLO, E. Le systémisme, nouvelle vision du monde. Paris / New York: Pergamon Press, 1981.

LAVILLE, J. L. Solidarité et développement durable. In: MARECHAL, J. P.; QUENAULT, B. Le développement durable. Rennes: Presses Universitaires de Rennes, 2005. 
LÉVÊQUE, C. et al. Les zones ateliers, des dipositifs pour la recherche sur l'environnement et les anthroposystèmes. Natures-Sciences-Sociétés, v. 8, n. 4, p. 44-52. 2000.

LOVELOCK, J. Healing Gaia. Practical medicine for the planet. New York: Harmony Books, 1991.

MCHARG, I. L. Design with nature. New York: Natural History Press, 1969.

MAGNAGHI, A. Local self-sustainable development: subjects of transformation. Tailoring Biotechnologies, v. 1, n. 1, p. 79-102. 2005.

MARÉCHAL, J. P. De la religion de la croissance à l'exigence de développement durable. Rennes: Presses Universitaires de Rennes, 2005.

MEADOWS, D. et al. The limits to growth. New York: Universe Books, 1972.

MEADOWS, D.; MEADOWS, D.; RANDERS, J. Les limites à la croissance (dans un monde fini). Paris: Editions Rue de l'Echiquier, 2004.

MERMET, L.; POUX, X. Pour une recherche prospective en environnement. Repères théoriques et méthodologiques. Natures, Sciences, Sociétés, v. 10, n. 3, p. 7-15. 2002.

MORIN, E. Ciência com consciência. Rio de Janeiro: Bertrand Brasil, 1996.

MORIN, E. O método. Porto Alegre: Editora Sulinas, 1998.

MORIN, E. Les sept savoirs nécessaires à l'éducation du futur. Paris: Le Seuil, 2000.

MORIN, E. Complexidade e ética da solidariedade. In: CASTRO, G. D.; CARVALHO, E. A.; ALMEIDA, M. C. Ensaios de complexidade. Porto Alegre: Sulina, 2002.

MORIN, E.; KERN, A. B. Terre Patrie. Paris: Seuil, 1993. 
MORIN, E.; LE MOIGNE, J. L. A inteligência da complexidade. São Paulo: Ed. Peirópolis, 2000.

NICHOLSON, M. The environmental revolution: a guide for the new masters of the world. London: Hodder \& Stoughton, 1970.

OLLAGNON, H. Estratégia patrimonial para a gestão dos recursos e dos meios naturais. Enfoque integrado da gestão do meio rural. In: VIEIRA, P. F.; WEBER, J. Gestão de recursos naturais renováveis e desenvolvimento. Novos desafios para a pesquisa ambiental. São Paulo: Cortez Editora, 2000. p. 171-200.

OLSSON, P.; FOLKE, C.; BERKES, F. Adaptive comanagement for building resilience in social-ecological systems. Environmental Management, v. 34, n. 1, p. 75-90. 2004.

OST, F. A natureza à margem da lei. A ecologia à prova do direito. Lisboa: Instituto Piaget, 1995.

PASSET, R. L'économique et le vivant. Paris: Payot, 1979.

PASSET, R. Desenvolvimento durável e biosfera: abertura multidimensional ou novos reducionismos? Revista Tempo Brasileiro, v. 108, p. 27-47. 1992.

PASSET, R. L'illusion néoliberale. Paris: Fayard, 2000.

PECQUEUR, B. Le développement local. Paris: Syros, 1989.

PECQUEUR, B. Le développement territorial: une nouvelle approche des processus de développement pour les économies du Sud. Grenoble: Institut de Géographie Alpine, 2004.

PECQUEUR, B. Le tournant territorial de l'économie globale. Revue Espace et Société, n. 124-125. 2006.

PECQUEUR, B.; VIEIRA, P. F. La création de ressources territoriales face au défi de l'environnement: une analyse du développement dans un scénario postfordiste. (No prelo). 2013. 
RAUD, C. O ecodesenvolvimento e o desenvolvimento territorial: problemáticas cruzadas. In: VIEIRA, P. F. et al. Desenvolvimento e meio ambiente no Brasil. A contribuição de Ignacy Sachs. Florianópolis: Pallotti / APED, 1998. p. 253-262.

REDDY, A. K. N. Problems in the generation and diffusion of appropriate technologies: a conceptual analysis. In: Science and technology for integrated development. Bangalore: Indian Institute of Science, 1977. p. 127-129.

SACHS, I. Stratégies de l'écodéveloppement. Paris: Les Editions Ouvrières, 1980.

SACHS, I. Espaços, tempos e estratégias de desenvolvimento. São Paulo: Vértice, 1986.

SACHS, I. Rumo à ecossocioeconomia. Teoria e prática do desenvolvimento. São Paulo: Cortez, 2007.

SACHS, I. et al. Germination studies of clay-coated sweet pepper seeds. Journal of American Society of Horticultural Science, v. 106, p. 385-389. 1981.

SEBILLOTTE, M. Les fondements épistémologiques de l'évaluation des recherches tournées vers l'action. Natures, Sciences, Sociétés, v. 9, n. 3, p. 8-15. 2001.

VIEIRA, P. F. Rumo ao desenvolvimento territorial sustentável: esboço de roteiro metodológico participativo. Eisforia, v.4, n. 4, p. 249-310. 2006.

VIEIRA, P. F.; RIBEIRO, M. A. Ecologia humana, ética e educação. A mensagem de Pierre Dansereau. Porto Alegre: Pallotti; Florianópolis: APED, 1999.

VIEIRA, P. F.; WEBER, J. Gestão de recursos naturais renováveis e desenvolvimento. Novos desafios para a pesquisa ambiental. São Paulo: Cortez, 2000 .

VIEIRA, P. F.; BERKES, F.; SEIXAS, C. S. Gestão integrada e participativa de recursos naturais. Conceitos, métodos e experiências. Florianópolis: APED Editora, 2005.

VIEIRA, P. F. et al. Universidade e desenvolvimento local : balanço da discussão. In: TREMBLAY, G.; VIEIRA, P. F. O papel da universidade no desenvolvimento local. Experiências brasileiras e canadenses. Florianópolis: APED / SECCO, 2011. p. 251-286. 
WEBER, J. Gestão de recursos renováveis: fundamentos teóricos de um programa de pesquisas. In: VIEIRA, P. F.; WEBER, J. Gestão de recursos naturais renováveis e desenvolvimento. Novos desafios para a pesquisa ambiental. São Paulo: Cortez, 2000. p. 115-146.

ZAOUAL, H. Socioéconomie de la proximité: du global au local. Paris: L'Harmattan, 2005.

Dossiê:

Recebido em: Outubro de 2013

Aceito em: Novembro de 2013 